\title{
The incidence and characteristics of homicides in elderly compared with non-elderly age groups in Johannesburg, South Africa
}

\author{
L Swart, DPhil (Psychology); S Buthelezi, MA (Psychology); M Seedat, DPhil (Psychology) \\ Institute for Social and Health Sciences, University of South Africa, Johannesburg, South Africa; and Violence, Injury and Peace \\ Research Unit, South African Medical Research Council/University of South Africa, Johannesburg, South Africa
}

Correspondingauthor: L Swart (swartl@unisa.ac.za)

\begin{abstract}
Background. Even though the rate of eldercide (homicide in the age group $\geq 60$ years) in South Africa (SA) is higher than the global rate, it receives little attention compared with homicide in younger $(<60$ years) age groups.

Objectives. To: (i) establish the proportion and rates of eldercide relative to homicide in young adult and middle-aged populations, and determine whether proportions of homicide across the age groups differ by race; and (ii) determine differences in homicide victim and incident characteristics across the three age categories and establish whether these differences vary by race.

Methods. This retrospective study analysed homicide data for adults (aged $\geq 15$ years) drawn from the National Injury Mortality Surveillance System (NIMSS) for the City of Johannesburg, SA $(2001$ - 2010). Percentages and rates were used to describe the incidence of eldercide (age $\geq 60$ years) relative to homicide in middle age ( 35 - 59 years) and youth (15 - 34 years). Eldercide and middle-age and youth homicides were compared by sex, race, weapon used, scene of injury, day of the week and time of death.

Results. For the 10-year period 2001 - 2010, NIMSS registered a total of 14678 adult homicide deaths for Johannesburg. Of these, a very small proportion (3.8\%) were eldercides, $46.9 \%$ were middle-age homicides, and the majority $(58.4 \%)$ were young adult homicides. The average annual eldercide rate $(23.1 / 100000)$ was also lower than the rate for the middle-aged (46.9/100 000) and young adult (58.4/100 000) groups. However, the difference in rates between the age groups decreased considerably over the study period. Race-specific patterns were observed in the distribution of homicide across age groups. Compared with the circumstantial patterns for youth and middle-age homicides, eldercide involved higher proportions of females and white victims, and greater use of blunt force and strangulation. Whereas homicides in the other age groups tended to occur in public spaces and during weekends and nights, eldercides occurred mainly in a home, during the week and during daytime.

Conclusions. The characteristics of eldercide differ from those of youth and middle-age homicides. The specificities of the circumstances suggest that interventions should take cognisance of the temporal and spatial dimensions of eldercide and go beyond the regular security and policing measures to ensure the safety of the elderly in Johannesburg.
\end{abstract}

S Afr Med J 2019;109(6):437-442. DOI:10.7196/SAMJ.2019.v109i6.13539

Eldercide, the death of a person aged $\geq 60$ years due to intentional injuries inflicted by another person, is an understudied public health and social problem in South Africa (SA). In contrast, much SA homicide research has highlighted the disproportionate involvement of youth, particularly black male youth, as both victims and perpetrators of homicide in the country. ${ }^{[1,2]}$ In 2009 , for instance, SA's eldercide rate was $25.2 / 100000$ for people aged $\geq 60$ years, compared with homicide rates of 56.7 per 100000 for young adults aged 15 - 29 years and 58.7 per 100000 for adults aged $30-44$ years. ${ }^{[3]}$ Notwithstanding these differences, SA's eldercide rate of 25.2/100 000 is considerably higher than the global average of $4.5 / 100000{ }^{[3,4]}$ In addition, SA's population aged $\geq 60$ increased from 3.2 million (7.3\%) in 2001 to 4.1 million (8.0\%) in 2011, suggesting that the safety of the elderly will need to be prioritised as a public health and social issue. ${ }^{[5]}$ It is estimated that by 2030 , there will be $\sim 7$ million elderly persons in SA. ${ }^{[5]}$

Declining physical strength and deteriorating health may limit older people's capacity to protect or remove themselves from violent situations that may result in fatal outcomes or the need for lengthy medical care. ${ }^{[6,7]}$ Eldercide may have devastating consequences for families and communities, especially when the elderly victim is the primary breadwinner or caregiver. ${ }^{[8,9]}$ Recent SA census figures indicate that approximately one in five (2.9 million) households is headed by an elderly person, and a third (32.5\%) of these have five or more members. ${ }^{[5]}$ Like other forms of violence, violence towards the elderly places a significant burden on the country's healthcare, social support and criminal justice systems. ${ }^{[10]}$

A small but growing body of research has emerged in SA and elsewhere to address aspects of the eldercide burden. While some studies describe the patterns of eldercide in the USA, ${ }^{[11,12]}$ a retrospective study analysed the incidence and epidemiological characteristics of eldercide in Johannesburg, SA. ${ }^{[13]}$ Other studies have highlighted how the demographics and situations of eldercide differ from those of youth homicide. ${ }^{[14-16]}$ These studies also indicate that the age distribution of homicide may differ according to race. ${ }^{[14-16]}$

\section{Objectives}

Following this body of research and in an attempt to highlight specific features of eldercide in SA, the current study compared the incidence and characteristics of eldercide ( $\geq 60$ years), youth homicide (15 34 years) and middle-age homicide ( 35 - 59 years) in Johannesburg for the period $2001-2010$. The specific objectives of this study 
clustered around two areas: $(i)$ to establish the proportion and rates of eldercide relative to youth and middle-age homicides, and determine whether the proportion of eldercide differed by race; and (ii) to determine the differences in victim and incident characteristics for eldercide and youth and middle-age homicide, and establish whether these differed by race. The study drew on Johannesburg non-natural death data for 2001 - 2010. Recognising that there is no universal definition of various age groups, we assumed elderly victims to be $\geq 60$ years old; this corresponds to the SA government's and the World Health Organization's definitions of elderly persons. ${ }^{[17,18]}$ Youth homicides covered young adults (15 - 34 years, which is consistent with the SA National Youth Policy definition of youth), and middleage homicides covered adults aged $35-59$ years.

\section{Methods}

The study consisted of a secondary analysis of adult ( $\geq 15$ years) homicide data registered by the National Injury Mortality Surveillance System (NIMSS) for the period 2001-2010 for Johannesburg, the only city for which NIMSS had full coverage of injury deaths for the study period. Violence is reported as among the leading causes of non-natural death annually in the city. NIMSS draws on statutory routine medicoforensic investigations at participating state medicolegal laboratories to collect epidemiological information on injury deaths. ${ }^{[19]}$ At each site, data collection forms are completed by forensic medical practitioners or forensic officers and captured into a database by administrative staff. The data are then sent to the Violence, Injury and Peace Research Unit (VIPRU), a national initiative co-directed by the South African Medical Research Council and the University of South Africa. VIPRU staff clean and combine data from various participating sites to create a single dataset.

NIMSS records information on victim demographics (age, sex and race), location and geographical place of injury, time of death, and external cause and apparent manner of death. The International Statistical Classification of Diseases and Related Health Problems, 10th revision (ICD-10) is used by NIMSS to classify the external cause of death, which refers to the mechanism or circumstance that led to the death. ${ }^{[17]}$ As the final manner of death can only be concluded after police investigations and court proceedings, NIMSS records the apparent manner of death as determined by the forensic medical practitioner.

\section{Data analysis}

Frequency counts, percentages and rates were used to describe the incidence and trends of homicide in the elderly relative to that in youth and middle age. Age-specific rates were calculated to examine the incidence over the study period. The rates were calculated for each year from 2001 to 2010 by dividing the number of homicide victims in the respective categories (e.g. those aged $\geq 60$ years) by the population of the relevant age group estimated for the City of Johannesburg, and multiplying that figure by 100000 . Population data for Johannesburg were obtained from Statistics South Africa's 2001 and 2011 censuses. The difference between the population figures for Census 2001 and Census 2011 was distributed across the years 2002 - 2010 to account for the growth in population numbers over the 10-year period. Frequency counts, percentages and rates were also calculated separately for black and white victims to determine whether the proportion of homicides in the elderly relative to those in younger age groups differed by race. Pearson's $\chi^{2}$ tests were used to establish whether differences in homicide characteristics between the older and younger victims were statistically significant.
Homicides were compared with regard to victim characteristics (sex and race) and incident characteristics (weapon used, location, day of week and time of day). Comparative analyses were also conducted separately for black and white victims to determine whether the differences in homicide characteristics for the older and younger age groups varied by race. A $p$-value $<0.05$ was regarded as statistically significant. Analyses were conducted with the Statistical Package for the Social Sciences (SPSS) for Windows, version 22 (IBM, USA).

\section{Ethical considerations}

The study constituted a secondary data analysis. The analysed data did not contain any identifying information regarding the victims. Ethical approval for the study was obtained from the University of South Africa Department of Psychology Ethics Committee (ref. no. 29-01-2013).

\section{Results}

\section{Incidence and trends in homicide deaths}

A total of 14678 homicide deaths involving individuals aged $\geq 15$ years were registered by NIMSS for Johannesburg for the 10 -year period. The elderly constituted a relatively small proportion $(n=557$, $3.8 \%$ ) of these homicides compared with the middle-aged ( $n=4878$, $46.9 \%$ ) and young ( $n=9153,58.4 \%)$ age groups (Table 1). Overall there was a slight increase in the proportion of homicides involving the elderly over the study period, from $3.4 \%$ in 2001 to $4.8 \%$ in 2010. In contrast, changes in the proportions of homicide among the younger age groups were notable; the proportion of middle-age homicides increased from $32.2 \%$ in 2001 to $43.1 \%$ in 2010 , and the proportion of youth homicides decreased from $64.4 \%$ to $52.1 \%$.

Table 1 also shows that the rate of homicides involving the elderly was lower than that for the middle-aged group and especially the youth age group, with an average annual rate of 23.1 per 100000 for the elderly, 46.9 per 100000 for the middle-aged group and 58.4 per 100000 for youth. Homicide rates declined over time for all age groups, with rates for the younger age groups dropping more rapidly than those for the elderly. As a result, the difference in homicide rates between the elderly and the middle-aged decreased from 31.9 in 2001 to 22.8 in 2010 , while the difference between the elderly and the young decreased from 53.0 in 2001 to 14.7 in 2010.

Table 2 shows that the proportion of homicides in the elderly and the age distribution of homicides varied according to race. The elderly accounted for only $2.1 \%$ of homicides in the black group and $3.2 \%$ of those among coloureds, with the young age group making up almost two-thirds of homicides in these groups (65.3\% among blacks and $64.0 \%$ among coloureds) and the middle-aged group making up almost a third (32.6\% and $32.8 \%$, respectively). Although the elderly proportion was larger $(8.3 \%)$ in the Indian population group, youth made up the majority of homicides (50.8\%), with the middle-aged group accounting for $41.0 \%$. In stark contrast, the elderly made up more than a quarter $(27.2 \%)$ of homicides in the white group, with the middle-aged group making up half $(50 \%)$ and the young age group $22.8 \%$. The number of eldercides $(n=239)$ also exceeded the number of youth homicides $(n=106)$ in the white group.

There was also considerable variation in the risk of homicide in the different age groups according to race. The eldercide rates for blacks and coloureds were low (21.6 per 100000 and 14.9 per 100000 , respectively) compared with rates of homicide in the two younger age groups (blacks 55.6 per 100000 for middle age and 67.0 for youth, and coloureds 32.9 and 45.7). The age disparities in rates among Indians were less stark, with figures of 21.7 per 100000 for the elderly, 
Table 1. Homicide victim numbers, percentages and rates by age group, Johannesburg, $2001-2010$

\begin{tabular}{|c|c|c|c|c|c|c|}
\hline \multirow[b]{3}{*}{ Year } & \multicolumn{6}{|c|}{ Age group } \\
\hline & \multicolumn{2}{|c|}{ Elderly ( $\geq 60$ years) } & \multicolumn{2}{|c|}{ Middle age (35 - 59 years) } & \multicolumn{2}{|c|}{ Young (15 - 34 years) } \\
\hline & $n(\%)$ & Rate/100 000 & $n(\%)$ & Rate/100 000 & $n(\%)$ & Rate/100 000 \\
\hline 2001 & $60(3.4)$ & 29.6 & $565(32.2)$ & 61.5 & $1132(64.4)$ & 82.6 \\
\hline 2002 & $51(3.1)$ & 24.1 & $505(30.6)$ & 53.0 & $1095(66.3)$ & 77.1 \\
\hline 2003 & $39(2.8)$ & 17.7 & $470(33.3)$ & 47.7 & $904(64.0)$ & 61.5 \\
\hline 2004 & $56(4.3)$ & 24.4 & $428(32.6)$ & 42.0 & $830(63.2)$ & 54.7 \\
\hline 2005 & $49(4.0)$ & 20.6 & $393(31.8)$ & 37.3 & $794(64.2)$ & 50.7 \\
\hline 2006 & $60(3.8)$ & 24.3 & $525(33.6)$ & 48.3 & $977(62.5)$ & 60.4 \\
\hline 2007 & $69(4.3)$ & 27.0 & $544(34.0)$ & 48.6 & $989(61.7)$ & 59.4 \\
\hline 2008 & $57(3.5)$ & 21.5 & $571(35.0)$ & 49.5 & $1005(61.5)$ & 58.6 \\
\hline 2009 & $57(4.5)$ & 20.8 & $444(34.9)$ & 37.4 & $772(60.6)$ & 43.8 \\
\hline 2010 & $59(4.8)$ & 20.9 & $533(43.1)$ & 43.7 & $645(52.1)$ & 35.6 \\
\hline Total & $557(3.8)$ & 23.1 & 4978 (33.9) & 46.9 & $9143(62.3)$ & 58.4 \\
\hline
\end{tabular}

Table 2. Homicide victim numbers, percentages and rates by race and age group, Johannesburg, 2001 - 2010

\begin{tabular}{|c|c|c|c|c|c|c|c|c|}
\hline \multirow[b]{3}{*}{ Age } & \multicolumn{8}{|c|}{ Race } \\
\hline & \multicolumn{2}{|c|}{ Black $(N=12539)$} & \multicolumn{2}{|c|}{ Coloured $(N=602)$} & \multicolumn{2}{|c|}{ Indian $(N=300)$} & \multicolumn{2}{|c|}{ White $(N=639)$} \\
\hline & $n(\%)$ & Rate/100 000 & $n(\%)$ & Rate/100 000 & $n(\%)$ & Rate/100 000 & $n(\%)$ & Rate/100 000 \\
\hline Elderly ( $\geq 60$ years) & $267(2.1)$ & 21.6 & $20(3.2)$ & 14.9 & $27(8.3)$ & 21.7 & $239(27.2)$ & 26.6 \\
\hline Middle age ( 35 - 59 years) & $4180(32.6)$ & 55.6 & $204(32.8)$ & 32.9 & $134(41.0)$ & 24.9 & $439(50.0)$ & 23.0 \\
\hline Young (15 - 34 years) & $8358(65.3)$ & 67.0 & $398(64.0)$ & 45.7 & $166(50.8)$ & 25.1 & $200(22.8)$ & 12.8 \\
\hline
\end{tabular}

24.9 for the middle-aged and 25.1 for the young age group. Among whites, the eldercide rate was higher $(26.6$ per 100000$)$ than the rate for youth homicide (12.8).

\section{Victim demographic and incident characteristics}

Table 3 compares victim and incident characteristics for eldercides and youth and middle-age homicides. Significantly different patterns among the age categories were observed for victim sex and race. Although males predominated among elderly $(76.8 \%)$, middle-aged (87.1\%) and young $(89.1 \%)$ victims, the proportion of males among the elderly was significantly smaller than in the younger age groups $\left(\chi^{2}=84.65\right.$, degrees of freedom $\left.(\mathrm{df})=4, p=0.000\right)$. Eldercides also comprised relatively similar proportions of black (47.9\%) and white (42.9\%) victims, whereas the overwhelming majority of victims of middle-age $(84.0 \%)$ and youth $(91.4 \%)$ homicide were black $\left(\chi^{2}=1716.59, \mathrm{df}=8, p=0.000\right)$.

Significant differences were also noted between the elderly and younger age groups with regard to homicide incident characteristics. While the most common method of killing in all homicides was with a firearm, the elderly were more likely to be killed by blunt force (27.3\%) and strangulation (9.3\%) compared with middle-aged (17.8\% and $1.6 \%$, respectively) and young $(13.6 \%$ and $1.3 \%)$ homicide victims $\left(\chi^{2}=358.13, \mathrm{df}=10, p=0.000\right)$.

The scene of homicide incidents was also significantly associated with age group, with more elderly victims killed at a place of residence $(45.2 \%)$ compared with middle-aged $(30.9 \%)$ and young victims $(28.3 \%)\left(\chi^{2}=101.87, \mathrm{df}=6, p=0.000\right)$. Stated differently, the proportion of elderly homicide victims killed in a street or road (13.5\%) and at 'unknown' locations (31.4\%) was lower than that of middle-aged (17.6\% and $41.5 \%$, respectively) and young $(21.2 \%$ and 41.2\%) homicide victims.

With regard to temporal patterns, eldercide incidents were more likely to occur during the week $(53.9 \%)$, whereas middle-age homicides (47.2\%) and youth homicides (41.6\%) occurred mainly over weekends $\left(\chi^{2}=66.29, \mathrm{df}=4, p=0.000\right)$. While the elderly were more likely to be killed during the day (06h00 - 17h59) (49.7\%), middle-age $(53.1 \%)$ and youth (59.2\%) homicides occurred mainly in the evening and at night $(18 \mathrm{~h} 00-05 \mathrm{~h} 59)\left(\chi^{2}=140.68, \mathrm{df}=4\right.$, $p=0.000$ ). Table 4 compares victim and incident characteristics for eldercides and youth and middle-age homicide by race (black/white). Comparative analyses were not conducted for Indian and coloured victims because the number of eldercides in these race groups was too small.

The pattern for black homicides was similar to that reported above for overall homicides. Although males comprised the vast majority of eldercides (80.9\%) and homicides in the younger age groups $(88.4 \%$ and $89.5 \%$ ), the proportion of male victims was significantly lower in eldercides $\left(\chi^{2}=23.39, \mathrm{df}=4, p=0.000\right)$. Among black victims, eldercides were also more likely to involve the use of blunt force (35.2\%) and strangulation (6.0\%) than middle-age (18.4\% and $1.4 \%)$ and youth homicides (13.9\% and $1.1 \%)$, where firearms and sharp instruments were more commonly used $\left(\chi^{2}=208.90, \mathrm{df}=10, p=0.000\right)$. With regard to the scene of homicide in the black group, a significantly greater proportion of eldercides $(37.1 \%)$ than middle-age $(30.0 \%)$ and youth homicides $(28.2 \%)$ occurred in a house, while the percentages of middle-aged (17.7\%) and young people (21.4\%) killed in a street or road were higher than the figure for older victims $(13.1 \%)\left(\chi^{2}=39.09\right.$, $\mathrm{df}=1, p=0.000$ ). Elderly black victims of homicide were significantly more likely to be killed during the week (53.2\%) than middle-aged $(46.4 \%)$ and young $(41.5 \%)$ black victims, who were more likely to be killed over the weekend $\left(\chi^{2}=39.65, \mathrm{df}=1, p=0.000\right)$. The elderly were also more likely to be killed during the day (06h00 - 17h59) (48.3\%) than middle-aged (35.9\%) and young (29.9\%) homicide victims, who were more likely to be killed during the evening or at night (18h00 05h59) $\left(\chi^{2}=80.80, \mathrm{df}=4, p=0.000\right)$.

Differences in victim and incident characteristics between the age groups were also noted among white homicides, although they were less pronounced than among black homicides. Eldercides among 
Table 3. Homicide victim and incident characteristics by age of victim, Johannesburg, 2001 - 2010

\begin{tabular}{|c|c|c|c|c|c|c|}
\hline \multirow[b]{2}{*}{ Characteristics } & \multicolumn{3}{|c|}{ Age } & \multirow[b]{2}{*}{$\chi^{2}$} & \multirow[b]{2}{*}{ df } & \multirow[b]{2}{*}{$p$-value } \\
\hline & $\begin{array}{l}\text { Elderly }(\geq 60 \text { years, } \\
N=557), n(\%)\end{array}$ & $\begin{array}{l}\text { Middle age ( } 35 \text { - } 59 \text { years, } \\
N=4978), n(\%)\end{array}$ & $\begin{array}{l}\text { Young }(15-34 \text { years, } \\
N=9143), n(\%)\end{array}$ & & & \\
\hline Sex & & & & 84.65 & 4 & 0.000 \\
\hline Male & $428(76.8)$ & 4337 (87.1) & $8148(89.1)$ & & & \\
\hline Female & 125 (22.4) & $620(12.5)$ & 978 (10.7) & & & \\
\hline Unknown & $4(0.7)$ & $21(0.4)$ & $17(0.2)$ & & & \\
\hline Race & & & & 1716.59 & 8 & 0.000 \\
\hline Black & 267 (47.9) & $4180(84.0)$ & 8358 (91.4) & & & \\
\hline White & 239 (42.9) & $439(8.8)$ & $200(2.2)$ & & & \\
\hline Coloured & $20(3.6)$ & $204(4.1)$ & $398(4.4)$ & & & \\
\hline Indian & $27(4.8)$ & $134(2.7)$ & $166(1.8)$ & & & \\
\hline Unknown & $4(0.7)$ & $21(0.4)$ & $21(0.2)$ & & & \\
\hline Weapon used & & & & 358.13 & 10 & 0.000 \\
\hline Firearm & $245(44.0)$ & 2857 (57.4) & $5487(60.0)$ & & & \\
\hline Sharp object & $83(14.9)$ & $1063(21.4)$ & 2148 (23.5) & & & \\
\hline Blunt object & $152(27.3)$ & $885(17.8)$ & 1240 (13.6) & & & \\
\hline Strangulation & $52(9.3)$ & $78(1.6)$ & $121(1.3)$ & & & \\
\hline Other & $14(2.5)$ & $59(1.2)$ & $94(1.0)$ & & & \\
\hline Unknown & $11(2.0)$ & $36(0.7)$ & $53(0.6)$ & & & \\
\hline Scene & & & & 101.87 & 6 & 0.000 \\
\hline House & $252(45.2)$ & 1538 (30.9) & $2584(28.3)$ & & & \\
\hline Road & 75 (13.5) & 875 (17.6) & $1942(21.2)$ & & & \\
\hline Other & $55(9.9)$ & $499(10.0)$ & $851(9.3)$ & & & \\
\hline Unknown & $175(31.4)$ & 2066 (41.5) & 3766 (41.2) & & & \\
\hline Day & & & & 66.29 & 4 & 0.000 \\
\hline Weekend & $257(46.1)$ & 2609 (52.4) & $5310(58.1)$ & & & \\
\hline Weekday & $300(53.9)$ & $2350(47.2)$ & 3803 (41.6) & & & \\
\hline Unknown & 0 & $19(0.4)$ & $30(0.3)$ & & & \\
\hline Time & & & & 140.68 & 4 & 0.000 \\
\hline Daytime & 277 (49.7) & $1812(36.4)$ & $2762(30.2)$ & & & \\
\hline Evening and night & 215 (38.6) & $2645(53.1)$ & 5417 (59.2) & & & \\
\hline Unknown & 65 (11.7) & $521(10.5)$ & $964(10.5)$ & & & \\
\hline
\end{tabular}

whites involved a significantly higher proportion of females $\left(\chi^{2}=6.70\right.$, $\mathrm{df}=2, p=0.035)$ and individuals who were killed by blunt force and strangulation $\left(\chi^{2}=14.14, \mathrm{df}=1, p=0.000\right)$, in a house $\left(\chi^{2}=39.09\right.$, $\mathrm{df}=1, p=0.000)$ and during the day $(06 \mathrm{~h} 00-17 \mathrm{~h} 59)\left(\chi^{2}=80.80, \mathrm{df}=4\right.$, $p=0.000$ ) compared with homicides in the middle-aged and younger groups. There was no significant difference regarding the time of the week, as white victims were more likely to be killed during the week than over the weekend, regardless of age.

\section{Discussion}

This study examined proportions and rates of homicide in the elderly relative to those in youth and middle age in the City of Johannesburg for the period 2001 - 2010, and compared the characteristics of all these homicides across race.

Overall, homicide in the elderly comprised a small proportion of homicides over the study period. Although there was a slight increase in the proportion of eldercides from $3.4 \%$ in 2001 to $4.8 \%$ in 2010 , the eldercide rate $(23.1$ per 100000$)$ was much lower than rates of homicide in youth (58.4 per 100000$)$ and middle age (46.9 per 100 000). Consistent with the considerable decrease observed in overall homicide rates in SA, particularly firearm homicide rates, homicide rates for all three age groups decreased over the study period. ${ }^{[20,21]}$ However, the decline was much greater in the younger age groups than in the elderly: the difference in homicide rates between the elderly and middle-aged groups decreased from 31.9 in 2001 to 22.8 in 2010, and the difference between the elderly and young age groups decreased from 53.0 to 14.7 over the same period. This finding may be explained by firearm homicide being a more important driver of homicide rates in youth and middle age than in the elderly.

Race-specific patterns in the distribution of homicide across age groups were also noted. Homicides in the black and coloured population groups were concentrated in the younger age groups, and there was a relatively small proportion of eldercide. In contrast, the proportion of eldercide as opposed to middle-age and youth homicide in the white group was relatively large. Black youth have the highest levels of unemployment in the country, and socioeconomic disparities appear to place this group at an increased risk of homicide. ${ }^{[22]}$

The study also found significant differences across the age groups with regard to victim demographics and incident characteristics. Compared with youth and middle-age homicides, eldercides involved a higher proportion of females, white victims, and individuals who died from non-firearm injuries (such as blunt force and strangulation), as well as victims who were killed at a home during the day. These differences in victim demographics and incident characteristics between the age groups were evident across race groups. It is possi- 


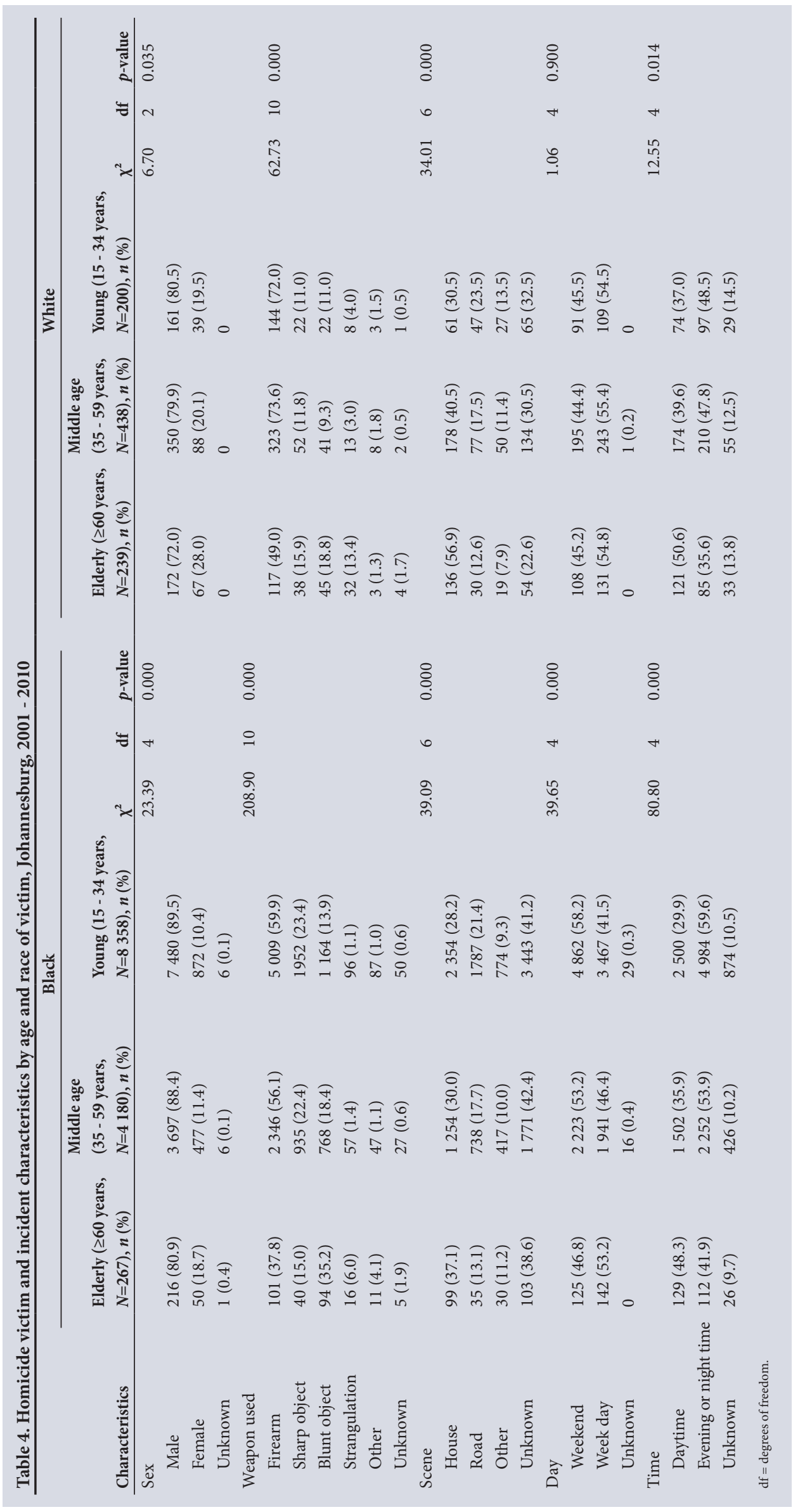

ble that racial differences in risk and circumstances become less important as age-related factors, such as physical deterioration and concomitant lifestyle changes, come to play a more central role in the lives of the elderly.

Sex differences in the risk of violence and homicide were much more prominent among youth than in the two older age groups, with males being significantly more likely to die from homicide than females, partly owing to issues related to masculinity. With health issues and physical impairments becoming more pertinent in the elderly, male gender may decrease in significance as a risk factor. ${ }^{[2,23]}$ The greater incidence of strangulation in the older than the younger age groups may also be explained by increased physical frailty in the elderly and their limited ability to defend themselves. ${ }^{[14]}$

Differences in scene and time of homicide across the age groups may in part be explained by differences in lifestyle and daily routine. Owing to retirement or physical weaknesses and impairments, elderly people may spend most of their time at home, and may often be alone, rendering them vulnerable to attacks inside the house. ${ }^{[12,14]}$ In contrast, young people often engage in social and entertainment activities linked to alcohol consumption in public places late at night, putting them at increased risk for violence and homicide in this setting. ${ }^{[14]}$

\section{Study limitations}

Our study has limitations. Although NIMSS currently provides the most detailed information available on fatal injuries in SA, missing data, particularly on the age of victims, mean that cases may have been excluded and that the analysis may therefore underestimate the true number of homicides. Misclassification may also threaten the accuracy of the data, especially in the case of the elderly, when there 
may be difficulties in differentiating between natural death, selfneglect and homicide. ${ }^{[7]}$ Furthermore, NIMSS data only focus on the victim. Additional studies are therefore needed to provide detailed information on perpetrators, including their demographic characteristics, the victim-perpetrator relationship and the motive for the violent assault. To assess the generalisability of our results, future research may examine trends and patterns of eldercide in other SA cities, and in rural areas, where rates of eldercide exceed the rates of homicides in younger age groups and also appear to be higher than those reported in urban areas. ${ }^{[24]}$

\section{Conclusions}

Despite the above limitations, this study offers insight into the magnitude and epidemiological (victim and incident) characteristics of eldercide relative to youth and middle-age homicide in Johannesburg in 2001-2010. Our findings suggest that those planning interventions should be alert to the temporal and spatial characteristics of eldercide in Johannesburg. Measures to secure the safety of elderly people, particularly females, in their homes appear to be critical. In addition to security considerations, interventions may need to look at how best to deal with the isolation and physical impairments that increase the risk of fatal consequences among the elderly.

\section{Declaration. None.}

Acknowledgements. The authors acknowledge the assistance of the forensic pathologists and personnel at the participating mortuaries, who made the data available for NIMSS.

Author contributions. LS contributed to the conception and design, performed the statistical analysis and interpretation of data, and contributed to drafting the article. SB contributed to the conception and design and drafting of the article. MS contributed to the conception and design and revising of the article for intellectual content. All authors read and approved the final version of the manuscript.

Funding. None.

Conflicts of interest. None.
1. Kramer S, Ratele K. Young black men's risk to firearm homicide in night time Johannesburg, South Africa: A retrospective analysis based on the National Injury Mortality Surveillance System. Afr Saf Arica. A retrospective an

2. Ratele K. Watch your man: Young black males at risk of homicidal violence. S Afr Crime Q 2010;33:19-24. Ratele K. Watch your man: Young black males at risk
https://doi.org/10.17159/2413-3108/2010/v0i33a88

3. Matzopoulos R, Prinsloo M, Pillay-van Wyk V, et al. Injury-related mortality in South Africa: A retrospective descriptive study of post-mortem investigations. Bull World Health Organ 2015;93(5):303-313. ttps://doi.org/10.2471/BLT.14.14577

4. World Health Organization. Global Status Report on Violence Prevention 2014. Geneva: WHO, 2014. Lehohla P. Census 2011: Profile of Older Persons in South Africa. Report No. 03-01-60. Pretoria: Statistics South Africa, 2014.

6. Chu LD, Kraus JF. Predicting fatal assault among the elderly using the national incident based reporting system crime. Homicide Stud 2004;8(2):70-95. https://doi.org/10.1177/1088767903262396

7. Crime and Misconduct Commission. Vulnerable Victims: Homicide of Older People, Issue 12. Brisbane: Crime and Misconduct Commission, 2013.

8. Anderson BA, Phillips HE. Trends in the Percentage of Children Who Are Orphaned in South Africa: 1995 - 2005. Report-03-09-062000. Pretoria: Statistics South Africa, 2006.

9. World Health Organization. Older Persons in Emergencies: An Active Ageing Perspective. Geneva: World Health 2008.

10. Brand S, Price R. The Economic and Social Cost of Crime (Home Office Research Study No. 217). London: Home Office, 2000

11. Bachman R, Meloy ML. The epidemiology of violence against the elderly: Implications for primary and secondary prevention. J Contemp Crim Justice 2008;24(2):186-197. https://doi. $\mathrm{org} / 10.1177 / 104398620831547$

12. Block RC. Homicide against or by the elderly in Chicago 1965 - 2000. Homicide Stud 2013;17(2):154-183. https://doi.org/10.1177/1088767913478596

13. Buthelezi S, Swart L, Seedat M. The incidence and epidemiology of eldercide in the city of Johannesburg, South Africa. J Forensic Leg Med 2017;52(Nov):82-88. https://doi.org/10.1016/j.jflm.2017.08.018

14. Abrams RC, Leon AC, Tardiff K, Sutherland K. 'Gray murder': Characteristics of elderly compared with non-elderly homicide victims in New York City. Am J Public Health 2007;97(9):1666-1670. https://doi. org/10.2105/AJPH.2005.079806

15. Addington LA. Who you calling old? Measuring 'elderly' and what it means for homicide research, Homicide Stud 2012;17(2):134-153. https://doi.org/10.1177/1088767912461784

16. Titterington VB, Reyes NC. Elder homicide in urban America: An exploratory analysis of Chicago, Titterington VB, Reyes NC. Elder homicide in urban America:
Houston, and Miami. Southwest J Crim Justice 2010;6(3):228-249.

17. Sethi D, Wood S, Mitis F, et al. European Report on Preventing Elder Maltreatment. Geneva: World Health Organization, 2011.

18. Wolf R, Daichman L, Bennet G. Abuse of the elderly. In: Krug E, Dahlberg LL, Mercy JA, Zwi AB, Lozano R, eds. World Report on Violence and Health. Geneva: World Health Organization, 2002:123-145.

19. South African Medical Research Council. A Profile of Fatal Injuries in Gauteng 2011: Annual report for Gauteng based on the National Injury Mortality Surveillance System (NIMSS). Cape Town: SAMRC, 2013.

20. Abrahams N, Jewkes R, Martin LJ, Mathews S. Guns and gender-based violence in South Africa. S Afr Med J 2010;100(9):586-588

21. Matzopoulos RG, Thompson ML, Myers JE. Firearm and nonfirearm homicide in 5 South African cities: A retrospective population-based study. Am J Public Health 2014;104(3):455-460. https://doi. org/10.2105/AJPH.2013.310650

22. Statistics South Africa. Quarterly Labour Force Survey (Quarter 1). P0211. Pretoria: Stats SA, 2018

23. Seedat $M$, van Niekerk A, Jewkes R, et al. Violence and injuries in South Africa: Prioritising an agenda for . Seedat M, van Niekerk A, Jewkes R, et al. Violence and injuries in South Africa: Prioritising an ag
prevention. Lancet 2009;374(9694):1011-1022. https://doi.org/10.1016/S0140-6736(09)60948-X

24. Sherriff B, MacKenzie S, Swart L, et al. A comparison of urban-rural injury mortality rates across two 4. Sherriff B, MacKenzie S, Swart L, et al. A comparison of urban-rural injury mortality rates across two
South African provinces, 2007. Int J Inj Contr Saf Promot 2015;22(1):75-85. https://doi.org/10.1080/1 7457300.2013 .870580

Accepted 8 January 2019 